\title{
Migraine and restless legs syndrome: current perspectives
}

This article was published in the following Dove Press journal:

Journal of Parkinsonism and Restless Legs Syndrome

15 November 2015

Number of times this article has been viewed

\section{Karen dos Santos Ferreira Fabíola Dach \\ Alan L Eckeli \\ José Geraldo Speciali \\ Department of Neurosciences and Behavioral Sciences, Division of Neurology, University Hospital, Medical School of Ribeirao Preto, University of São Paulo, São Paulo, Brazil}

Correspondence: Karen dos Santos Ferreira

Department of Neurosciences and Behavioral Sciences, Division of Neurology, University Hospital, Medical School of Ribeirao Preto, University of São Paulo, Avenida Bandeirantes, 3900, CEP 14.048-900, Ribeirao Preto, São Paulo, Brazil

Tel +55 II I6 36022548

Fax +55 II 1636022548

Email karenferreira@usp.br
Abstract: The relationship between migraine and restless legs syndrome (RLS) has been described in the literature for some years, based on clinical findings and pathophysiological considerations. There are some possible factors relating migraine and RLS. Both are diseases involving the central nervous system, the two diseases seem to share a dopaminergic mechanism, and it is also believed that they may share a genetic origin. At present, doctors who work with these two diseases should be encouraged not to simply investigate the simultaneous presence of both, but should also apply a treatment better adapted to this possibility. Research should be directed at some still unanswered questions for a better understanding of the association between migraine and RLS.

Keywords: migraine, restless legs syndrome, physiopathology, comorbidities

\section{Introduction}

Restless legs syndrome (RLS) also known as Willis-Ekbom disease was first defined as a new syndrome in 1944 in Sweden by Karl-Axel Ekbom, with the description of four essential characteristics based on eight clinical cases. Ekbom was a renowned neurologist known for various articles on neurological topics. He also studied about the pain, headache, and specifically migraine. ${ }^{1,2}$

Over the last two decades, RLS has attracted interest in the medical area because of its prevalence and repercussions, and recent studies dealing with its epidemiology, physiopathology, genetics, and clinical consequences have been of help for a better understanding of the condition. ${ }^{3-5}$

RLS is characterized by an urgent need to move the lower limbs associated with discomfort described as dysesthesia in the legs. The intensity of the symptoms is greater during rest, at the end of the afternoon, and at night, and the symptoms are relieved by movement of the affected region. ${ }^{3-5}$

Despite his interest in the study of migraine, initially Karl-Axel Ekbom did not try to correlate this type of headache with the syndrome affecting the legs. At that time, some mechanisms involving dopaminergic pathways, possibly representing an intersection of the two diseases, had not yet been elucidated. ${ }^{1}$ Over the last few years, the association of RLS with headaches, and migraine in particular, has been described in several studies.

\section{Migraine and RLS physiopathology}

There are some possible factors relating migraine and RLS. ${ }^{6}$ First of all, both are diseases involving the central nervous system. Central sensitization in chronic migraine 
(via the trigeminocervical nucleus in the brain stem) may be a facilitator of the sensory symptoms related to RLS. In addition, the two diseases seem to share a dopaminergic mechanism. While migraine patients seem to have D2-like hypersensitivity of dopaminergic receptors and dysfunction of $\mathrm{D} 2$ receptors at the level of the brain stem, in RLS there is dysfunction of $\mathrm{D} 2$ receptors at the level of base nuclei. Thus, the hypothesis has been raised that D2 receptors in other brain regions may be hypersensitive, facilitating migraine crises. ${ }^{7,8}$

It is also believed that the two diseases may share a genetic origin. Bonati ${ }^{9}$ suggested a genetic link common to the two diseases mapped to chromosome $14 \mathrm{q} 21$. This origin was described in an Italian family with an autosomal dominant familial form of RLS. However, Soragna ${ }^{10}$ reported genetic susceptibility to migraine without aura, also related to chromosome $14 q 21$, with no description of RLS in these patients.

\section{Migraine and RLS association studies}

The first study relating migraine and RLS was published in 2003 by Young et al. ${ }^{11}$ In 2007 , Rhode et a ${ }^{12}$ detected a significantly higher frequency of RLS in patients with migraine than in control patients $(17.3 \%$ vs $5.6 \%, P<0.001)$. The cited study had some weak points, mainly regarding subject selection since subjects with chronic migraine or taking migraine medications that might influence the dopaminergic pathways and facilitate the presence of RLS were not excluded. ${ }^{12}$

D'Onofrio et $\mathrm{al}^{13}$ detected a $22.4 \%$ prevalence of RLS in 200 patients with headaches compared with a prevalence of $8.3 \%$ in controls. The scores on anxiety and depression scales were higher for patients with RLS and there was no correlation with obesity or specific characteristics of migraine.

Another study detected an $11.4 \%$ prevalence of RLS in 772 patients with migraine, who also showed a higher prevalence of nausea, photophobia, phonophobia, and vertigo and higher scores on anxiety and depression scales (Hospital Anxiety and Depression Scale) and no Migraine Disability Assessment. $^{14}$

In addition, patients with migraine and RLS comorbidity have more dopaminergic symptoms related to migraine (nausea, vertigo) compared with controls. ${ }^{15}$

Population studies have reported similar magnitudes of findings of RLS/migraine association in male and female populations. The association was not modified by other factors such as age, ethnic group, presence of depression, anxiety, sleep quality, Parkinson's disease, iron supplementation, smoking habit, alcohol drinking, hypertension, or body mass index. The presence or absence of aura also had no influence on the findings. ${ }^{16-18}$

More recently, the inverse relationship has been investigated, showing that $15.1 \%$ of 265 patients with RLS had migraine. Although this prevalence was not higher than that for the population in general, RLS was more severe in these patients and a family history of RLS was more common in patients with RLS and migraine. Another study conducted on 47 patients with RLS showed that $53.2 \%$ of them had migraine. ${ }^{19,20}$

Finally, a systematic review of the topic reported that previous studies suggested that RLS is more frequent among patients with migraine, with plausible hypotheses explaining this association. ${ }^{21}$ The objective of the present study was to summarize the advances in the investigation of the relationship between migraine and RLS and to analyze the next steps to be taken in this interesting area of research.

\section{Migraine}

Migraine is a common neurological disease affecting $10 \%-20 \%$ of the world population. ${ }^{22}$ The peak of prevalence is located around 30-50 years of age, with a 2.2:1 predominance among females. More than $70 \%$ of the patients have at least one direct relative affected by migraine. ${ }^{23,24}$ The International Classification of Headache Disorders defines migraine as a recurrent headache manifesting in crises of throbbing or pulsating pain of moderate to strong intensity that worsens with daily activities, lasting 4-72 hours. The pain is unilateral in two-thirds of the cases and may be accompanied by nausea, vomiting, photophobia, and phonophobia. ${ }^{25}$

The physiopathology of migraine is based on cerebral hyperexcitability of probable polygene inheritance and with incomplete penetrance. After exposure to certain triggering factors, there is the release of neurotransmitters such as bradykinin, nitric oxide, substance $\mathrm{P}$, and calcitonin gene-related peptide in meningeal vessels, causing increased vascular permeability and resulting in an inflammatory reaction. The trigeminal afference carries this pain to the thalamus and later to the cerebral cortex, where it becomes conscious. ${ }^{26}$

The dopaminergic involvement in the pathogenesis of migraine is characterized by hypersensitivity of D2-like receptors. Migraineurs are considered to be hypersensitive to dopamine, which may be responsible for symptoms such as nausea, irritability, and vertigo and also for the symptoms of the premonitory phase of the crisis. Dopamine is also involved in the vasodilation of cranial arteries. There are five types of dopaminergic receptors, classified as D1 like (D1 and D5) and D2 like (D2, D3, and D4). Drugs that 
antagonize D2 receptors are known to act positively in the treatment of migraine. ${ }^{7,27}$

In addition, a large number of diseases have been associated with migraine, including fibromyalgia, ${ }^{28}$ depression, ${ }^{29}$ sleep disorders, ${ }^{30,31}$ and other disturbances of movement mediated by dopaminergic pathways. ${ }^{32,33}$ These associations suggest that migraine may share physiopathological aspects with other diseases, stimulating the investigation of these comorbidities.

\section{Restless legs syndrome}

The prevalence of RLS has been estimated at $5 \%-10 \%$ of the world population, with ethnic and geographic differences. ${ }^{3}$ A prevalence of $0.1 \%$ has been observed in Singapore, ${ }^{34}$ $3.19 \%$ in Turkey, ${ }^{35} 6.77 \%$ in Mozambique (Africa), ${ }^{36}$ and $6.4 \%$ in Brazil. ${ }^{37}$ The different prevalence rates observed in epidemiological studies were probably due to many factors such as ethnic composition of the population, environmental influence, and also the methodology used to obtain the data.

As is the case for migraine, there is a higher prevalence of RLS among women, at a ratio of two women to one man and, in contrast to migraine, the prevalence of the condition increases with age. ${ }^{3,4}$ Approximately $70 \%$ of the cases are primary forms (genetically inherited or idiopathic), while the remaining ones are symptomatic (secondary to other conditions such as iron-deficiency anemia, peripheral neuropathies, pregnancy, and uremia). 3,4

The first genetic locus demonstrating association with RLS was mapped to chromosome $12 \mathrm{q} .{ }^{38}$ At least four other loci have been described (14q, 9p, 2q, 20p). ${ }^{39}$ More recently, susceptibility to RLS was demonstrated in five genes (chromosomes 2, 6, 9, 15, and 16). ${ }^{40}$ These findings suggest a variable phenotypic expression resulting in clinical heterogeneity.

The diagnosis of RLS is exclusively clinical and has been established by the International Restless Legs Syndrome Study Group ${ }^{3}$ based on the presence of four clinical criteria: intense and irresistible wish to move the legs usually associated with paresthesias or dysesthesias in the legs; worsening of symptoms during rest; total or partial relief by movement; and worsening at the end of the day and at night. Criteria supporting the diagnosis are the presence of periodic leg movements, a family history of the disease, and a therapeutic response to dopaminergic agents. $^{3}$

The physiopathology of RLS includes a dysfunction of dopaminergic mechanisms and the possibility that iron deficiency may alter the cell function of D2 dopaminergic receptors in specific areas such as base nuclei, nigrostriatal region, and nucleus ruber. ${ }^{8}$ In this respect, low ferritin levels have been observed in patients with RLS, indicating the presence of low iron store levels. ${ }^{41,42}$ It should be remembered that iron is also an important cofactor in the synthesis of dopamine. Thus, iron deficiency may induce changes in dopaminergic signaling. In-depth studies of the relationship between RLS and iron have been reported in the literature. In addition, Yucel et $\mathrm{al}^{43}$ believe that low iron levels may be associated with the pathophysiology of migraine detected in patients with RLS. Gupta et $\mathrm{al}^{44}$ believe that iron dysmetabolism and increased serum phosphorus levels could be a link between migraine and RLS.

Several comorbidities related to RLS have been reported in the literature, such as sleep disorders, ${ }^{45}$ depressive disorder, ${ }^{45}$ fibromyalgia, ${ }^{46}$ diabetes mellitus, ${ }^{47}$ and peripheral neuropathies. ${ }^{48}$ Since some of these comorbidities are also more frequent in migraine, this would be an interesting point for the investigation of the causal relationship between the two diseases. ${ }^{49}$

A curious topic is the treatment of RLS and its possible relationship with migraine. The treatment of RLS is indicated for patients with important symptoms that may interfere with sleep and the quality of life. Three main classes of medications can be used: dopaminergic agonist agents, opioids, and alpha-delta ligands. The dopaminergic agents (pramipexole, ropinirole, rotigotine) are considered to be first choice for the treatment of RLS. However, the use of dopaminergic medications for the treatment of RLS may trigger migraine crises. On the other hand, the use of medications with an antidopaminergic action for the treatment of migraine such as neuroleptics and antiemetics may also trigger or worsen RLS. ${ }^{7,8}$

Regarding the alpha-delta ligands, pregabalin has been shown to be clinically effective, as demonstrated in clinical trials for the treatment of migraine and RLS..$^{50,51}$

\section{Discussion and current perspectives}

The relationship between migraine and RLS has been described in the literature for some years, based on clinical findings and pathophysiological considerations. Two recent well-designed population cohort studies have supported these findings, ${ }^{16-18}$ previously reported in case series and in case-control studies ${ }^{12-15,19,20}$ (Table 1). A systematic review and meta-analysis of studies investigating RLS in headache/ migraine and vice versa was performed and identified 24 
Table I Studies about migraine and RLS, 2003-20I4

\begin{tabular}{|c|c|c|c|c|c|}
\hline Study & Year & $\mathbf{N}$ (patients) & RLS in migraine (\%) & RLS in controls (\%) & $P$-value/OR \\
\hline Young et al" & 2003 & 50 & $4 \mid(82)$ & $17(34)$ & $P<0.001$ \\
\hline Rhode et al ${ }^{\prime 2}$ & 2007 & 411 & 7I (17.3) & $23(5.6)$ & $P<0.00$ I \\
\hline$D^{\prime}$ Onofrio et $\mathrm{al}^{13}$ & 2008 & 200 & $44(22.4)$ & $16(8.3)$ & $P<0.002$ \\
\hline Cologno et al ${ }^{15}$ & 2008 & 164 & $164(100)$ & $4 \mathrm{I}(25.3)$ & $P<0.00$ I \\
\hline Chen et $\mathrm{a}^{14}$ & 2009 & $|, 04|$ & $772(74.1)$ & $118(11.4)$ & $P<0.002$ \\
\hline Ferreira et al & 2013 & 72 & $18(25)$ & $5(8)$ & $P<0.01$ \\
\hline Winter et $\mathrm{al}^{16}$ & 2013 & 22,926 & $2,816(12.3)$ & I,7। 7 (7.5) & $\mathrm{OR}=1.20(1.04-1.38)$ \\
\hline Schurks et al ${ }^{17}$ & 2012 & 31,370 & $6,857(21.9)$ & $996(14.5)$ & $\mathrm{OR}=1.22(1.13-1.32)$ \\
\hline Zanigni et $\mathrm{a}^{18}$ & 2014 & $\mathrm{I}, 567$ & $20(12.6)$ & $139(9.6)$ & $\mathrm{OR}=1.79(1.00-3.19) \quad P=0.049$ \\
\hline Fernandez-Matarrubia et $\mathrm{al}^{20}$ & 2014 & 47 & $25(53.2)^{*}$ & $47(100)^{* *}$ & $P=0.19$ \\
\hline Gozubatik-Celik et al ${ }^{19}$ & 2014 & 265 & $40(15.1)^{*}$ & $265(100)^{* *}$ & $* * *$ \\
\hline
\end{tabular}

Notes: *Migraine in RLS patients; **all have RLS; ***not described.

Abbreviations: OR, odds ratio; RLS, restless legs syndrome.

studies. RLS prevalence in migraine ranged from $8.7 \%$ to $39.0 \%$ and migraine prevalence in RLS ranged from $15.1 \%$ to $62.6 \% .{ }^{52}$ The prevalence of migraine, however, is a different point of study. ${ }^{19}$ From a clinical viewpoint, both diseases are characterized by their chronic nature, with periodic exacerbations, involving women and having an important impact on the quality of life and on sleep. In addition, there are physiopathological and genetic bases that support the plausibility of this relationship. Thus, from a scientific perspective, what possible factors could be analyzed when relating migraine and RLS?

First of all, both diseases involve the central nervous system and mechanisms of sensory and/or pain perception. The repeated activation of sensitive pathways in both diseases may lead to central sensitization (via the trigeminocervical nucleus in the brain stem) and to the facilitation of perception of painful/sensory stimuli. This theory has been previously considered and may also explain the presence of other painful syndromes such as fibromyalgia associated with the migraine/RLS binomial. ${ }^{6}$

Second, there is dopaminergic involvement in both conditions. In RLS, there seems to be involvement of dopaminergic A11 cells in the hypothalamus and dysfunction of $\mathrm{D} 2$ receptors in base nuclei, with the possible presence of hypersensitivity of these receptors in other brain areas, as is also the case for the pathogenesis of migraine. ${ }^{6-8} \mathrm{In}$ addition, A11 cells may be able to inhibit the activation of the trigeminocervical complex, which is an important region for pain transmission in migraine..$^{53}$ Another point of connection between the diseases is the iron metabolism. Iron is an important cofactor in the synthesis of dopamine. Low ferritin rates may be associated with RLS. Moreover, it is known that chronic migraine has iron deposit in the periaqueductal gray, indicating altered metabolism of the element in the brain. Would be iron deposit decreased as tyrosine cofactor in D2 receptor, facilitating RLS? ?1-44 $^{41}$

Third, a possible genetic link exists for the two diseases, mapped to chromosome $14 \mathrm{q} 21 .{ }^{9}$ This is an important point for scientific investigation in future studies.

Fourth, the two diseases have common comorbidities. ${ }^{49}$ Sleep disorders as well as insomnia and sleep deprivation, which may trigger migraine, are more frequent in patients with RLS. Depressive disorder is more frequent in patients with migraine than in patients with RLS. The functional impairment caused by these diseases is believed to be the cause of depressive disorder. In previous studies that performed multivariable analysis with models adjusted for comorbidities such as depression, anxiety, sleep disorders, diabetes, obesity, and smoking habit, the relationship between migraine and RLS was not modified. ${ }^{16-18}$ On the other hand, in another study, logistic regression analysis revealed that RLS comorbidity in migraine patients was associated with insomnia, daytime sleepiness, depressive symptoms, headache-related disability, and increased serum phosphorus levels. ${ }^{54}$ Appropriate treatment of the presence of associated depressive disorder may lead to an overall improvement of the patients.

Another important aspect is the use of medications. Patients with migraine use more medications in a chronic manner, especially some that can influence the dopaminergic pathways facilitating the presence of RLS. Also, patients with RLS use dopaminergic agonist medications that may worsen the crises of migraine. In these cases, should we avoid medication with a dopaminergic action and prefer alpha-delta ligand agents (pregabalin), which may act by improving both diseases $?^{90,51}$ 
Finally, a multidimensional approach to the management of chronic diseases such as migraine and RLS also includes nonpharmacological treatments such as the practice of physical exercises in both situations. Previous studies have reported that the practice of a program of physical conditioning with aerobic exercises at a frequency of three times a week improves the symptoms of both migraine and RLS. ${ }^{55,56}$ Thus, it would be interesting to recommend these exercises routinely to patients with this comorbidity.

What are the current perspectives and what should future studies look for? The relationship between migraine and RLS has been well documented in the literature and doctors who work with these two diseases should be encouraged not to simply investigate the simultaneous presence of both, but to also apply a treatment better adapted to this possibility. The presence of associated depressive disorder should also be properly treated and preventive strategies of benefit for both diseases should be stimulated, together with sleep hygiene habits and regular physical activity.

Regarding research, there still are some unanswered questions. In the basic area, the physiopathological mechanisms related to these comorbidities are still being elucidated. In addition, the possible genetic association between the two diseases still requires further study. In the clinical interface, there still are some points that have not been clarified. Does effective treatment of RLS influence the improvement of migraine and vice versa? A single study that assessed the effect of RLS treatment on the improvement of migraine detected that only $30 \%$ of the patients with migraine reported improvement of migraine after RLS treatment. ${ }^{18}$ What could be the best therapeutic approach for these cases? In clinical practice, an appropriate evaluation of the medications used by these patients is essential for successful treatment, although these questions are still open to new studies and investigations. We believe that new clinical trials on patients affected by the two conditions could help us to find out which medication would be the most appropriate in this situation.

\section{Conclusion}

The relationship between migraine and RLS has been well documented in the literature. At present, doctors who work with these two diseases should be encouraged not to simply investigate the simultaneous presence of both, but should also apply a treatment better adapted to this possibility. And research should be directed at some still unanswered questions for a better understanding of the association between migraine and RLS.

\section{Disclosure}

The authors did not have financial support for this research. All expenses were funded by the researchers. The authors report no conflicts of interest in this work.

\section{References}

1. Karroum E, Konofal E, Arnulf I. Karl-Axel Ekbom (1907-1977) J Neurol. 2009;256:683-684.

2. Ekbom KA. Asthenia crurum paraesthetica ('irritable legs'). A new syndrome consisting of weakness, sensation of cold and nocturnal paraesthesia in the legs, responding to a certain extent to treatment with Priscol and Doryl - a note on paresthesia in general. Acta Med Scand. 1944;118:197-209.

3. Allen RP, Pichietti D, Hening WA, Trenkwaldera C, Walters AS, Montplaisir J. Restless legs syndrome: diagnostic criteria, special considerations, and epidemiology. A report from the restless legs syndrome diagnosis and epidemiology workshop at the National Institutes of Health. Sleep Med. 2003;4(2):101-119.

4. Trenkwalder C, Paulus W, Walters AS. The restless legs syndrome. Lancet Neurol. 2005;4(8):465-475.

5. Merlino G, Valente M, Serafini A, Gigli GL. Restless legs syndrome: diagnosis, epidemiology, classification and consequences. Neurol Sci. 2007;28(1):37-46.

6. Sabayan B, Bagheri M, Haghighi AB. Possible joint origin of restless leg syndrome (RLS) and migraine. Med Hypotheses. 2007;69(1):64-66.

7. Akerman S, Goadsby PJ. Dopamine and migraine: biology and clinical implications. Cephalalgia. 2007;27(11):1308-1314.

8. Cervenka S, Palhagen SE, Comley RA, et al. Support for dopaminergic hypoactivity in restless legs syndrome: a PET study on D2-receptor binding. Brain. 2006;129(8):2017-2028.

9. Bonati MT. Autosomal dominant restless legs syndrome maps on chromosome 14 q. Brain. 2003;126(6):1485-1492.

10. Soragna D. A locus for migraine without aura maps on chromosome 14q 21.2-q 22.3. Am J Hum Genet. 2003;72(1):161-167.

11. Young WB, Piovesan E, Biglan KM. Restless legs syndrome and drug induced akathesia in headache patients. CNS Spectr. 2003;6: 450-456.

12. Rhode AM, Hösing VG, Happe S, Biehl K, Young P, Evers S. Comorbidity of migraine and restless legs syndrome - a case-control study. Cephalalgia. 2007;27(11):1255-1260.

13. D’Onofrio F, Bussone G, Cologno D, et al. Restless legs syndrome and primary headaches: a clinical study. Neurol Sci. 2008;29:169-172.

14. Chen PK, Fuh JL, Chen SP, Wang SJ. Association between restless legs syndrome and migraine. J Neurol Neurosurg Psychiatry. 2009;81(5): $1-14$.

15. Cologno D, Cicarelli G, Petretta V, Onofrio F, Bussone G. High prevalence of dopaminergic premonitory symptoms in migraine patients with restless legs syndrome: a pathogenetic link? Neurol Sci. 2008;29:166-168.

16. Winter AC, Schurks M, Berger K, et al. Migraine and restless legs syndrome in men. Cephalalgia. 2013;33(2):130-135.

17. Schurks M, Winter AC, Berger K, Buring JE, Kurth T. Migraine and restless legs syndrome in women. Cephalalgia. 2012;32(5):382-389.

18. Zanigni S, Giannini G, Pattaro C, et al. Association between restless legs syndrome and migraine: a population-based study. Eur J Neurol. 2014;21(9):1205-1210.

19. Gozubatik-Celik G, Benbir G, Tan F, Karadeniz D, Goksan B. The prevalence of migraine in restless legs syndrome. Headache. 2014; 54(5):872-877.

20. Fernandez-Matarrubia M, Cuadrado ML, Sanchez-Barros CM, et al. Prevalence of migraine in patients with restless legs syndrome: a casecontrol study. Headache. 2014;54(8):1337-1346.

21. Cannon PR, Larner AJ. Migraine and restless legs syndrome: is there an association? J Headache Pain. 2011;12(4):405-409. 
22. Haut SR, Bigal ME, Lipton RB. Chronic disorders with episodic manifestations: focus on epilepsy and migraine. Lancet Neurol. 2006;5: $148-157$.

23. Becker WJ, Gladstone JP, Aubé M. Migraine prevalence, diagnosis, and disability. Can J Neurol Sci. 2007;34(4):3-9.

24. Rasmussen BK. Epidemiology of headache. Cephalalgia. 2001; 21(7):774-777.

25. Headache Classification Committee of the International Headache Society (IHS). The International Classification of Headache Disorders: 3nd edition. Cephalalgia. 2013;33(9):644-658.

26. Goadsby PJ, Lipton RB, Ferrari MD. Migraine - current understanding and treatment. $N$ Engl J Med. 2002;346(4):257-270.

27. Akerman S, Goadsby PJ. The role of dopamine in a model of trigeminovascular nociception. J Pharmacol Exp Ther. 2005;314(1):162-169.

28. Ifergane G, Buskila D, Simiseshvely N, Zeev K, Cohen H. Prevalence of fibromyalgia syndrome in migraine patients. Cephalalgia. 2006; 26(4):451-456.

29. Breslau N, Lipton RB, Stewart WF, Schultz LR, Welch KM. Comorbidity of migraine and depression: investigating potential etiology and prognosis. Neurology. 2003;60(8):1308-1312.

30. Dahmen N, Kasten M, Wieczorek S, Gencik M, Epplen JT, Ullrich B. Increased frequency of migraine in narcoleptic patients: a confirmatory study. Cephalalgia. 2003;23(1):14-19.

31. Paiva T, Batista A, Martins P, Martins A. The relationship between headaches and sleep disturbances. Headache. 1995;35(10):590-596.

32. CuboE, Kompoliti K, Leurgans SE, Raman R. Dopaminergic hypersensitivity in patients with Parkinson disease and migraine. Clin Neuropharmacol. 2004;27(1):30-32.

33. Duval C, Norton L. Tremor in patients with migraine. Headache. 2006;46(6):1005-1010.

34. Tan EK, Seah A, See SJ, Lim E, Wong MC, Koh KK. Restless legs syndrome in an Asian population: a study in Singapore. Mov Disord. 2001;16(3):577-579.

35. Sevim S, Dogu O, Camdeviren H, et al. Unexpectedly low prevalence and unusual characteristics of RLS in Mersin, Turkey. Neurology. 2003;61(11):1562-1569.

36. Ferreira KF, Eckeli A, Dach F, Schwalbach MT, Schwalbach J, Speciali JG. Prevalence of restless legs syndrome in patients with chronic pain in Maputo, Mozambique. Sleep Med. 2013;14(12):1417-1418.

37. Eckeli AL, Gitaí LG, Dach F, et al. Prevalence of restless legs syndrome in the rural town of cassia dos coqueiros in Brazil. Sleep Med. 2011; 12(8):762-767.

38. Desautels A, Turecki G, Montplaisir J, et al. Restless legs syndrome: confirmation of linkage to chromosome 12q, genetic heterogeneity, and evidence of complexity. Arch Neurol. 2005;62(4):591-596.

39. Pichler I, Hicks AA, Pramstaller PP. Restless legs syndrome: an update on genetics and future perspectives. Clin Genet. 2008;73(4):297-305.
40. Moore H, Wilkelmann J, Lin L, et al. Periodic leg movements during sleep are associated with polymorphisms in BTBD9, TOX3/BC034767, MEIS1, MAP2K5/SKOR1, and PTPRD. Sleep. 2014;37(9):1535-1542.

41. Earley CJ, Barker PB, Horská A, Allen RP, et al. MRI-determined regional brain iron concentrations in early- and late-onset restless legs syndrome. Sleep Med. 2006;7(5):458-461.

42. Sun ER, Chen CA, Ho G, Earley CJ, Allen RP. Iron and the restless legs syndrome. Sleep. 1998;21(4):371-377.

43. Yucel M, Akgün H, Oz O, Demirkaya S. Migraine and restless leg syndrome co-morbidity may be due to iron deficiency. Ann Indian Acad Neurol. 2013;16(3):461.

44. Gupta R, Spence DW, Bahammam AS, Monti JM, Padi-perumal SR. Association between migraine and restless legs syndrome. Somnologie. 2014;18(2):121-126.

45. Picchietti D, Winkelman JW. Restless legs syndrome, periodic limb movements in sleep, and depression. Sleep. 2005;28(7):891-898.

46. Yunus MB, Aldag JC. Restless legs syndrome and leg cramps in fibromyalgia syndrome: a controlled study. BMJ. 1996;312(7042):1339.

47. Gemignani F, Brindani F, Vitetta F, Marbini A, Calzetti S. Restless legs syndrome in diabetic neuropathy: a frequent manifestation of small fiber neuropathy. J Peripher Nerv Syst. 2007;12(1):50-53.

48. Gemignani F, Brindani F, Negrotti A, Vitetta F, Alfieri S, Marbini A. Restless legs syndrome and polyneuropathy. Mov Disord. 2006; 21(8):1254-1257.

49. Ferreira KS, Eckeli A, Dach F, Speciali JG. Comorbidities, medications and depressive symptoms in patients with restless legs syndrome and migraine. Arq Neuropsiquiatr. 2013;71(2):87-91.

50. Pizzolato R, Villani V, Prosperini L, Ciuffoli A, Sette G. Efficacy and tolerability of pregabalin as preventive treatment for migraine: a 3-month follow-up study. J Headache Pain. 2011;12(5):521-525.

51. Allen R, Chen C, Soaita A, et al. A randomized, double-blind, 6-week, dose-ranging study of pregabalin in patients with restless legs syndrome. Sleep Med. 2010;11(6):512-519.

52. Schürks M, Winter A, Berger K, Kurth T. Migraine and restless legs syndrome: a systematic review. Cephalalgia. 2014;34(10):777-794.

53. Charbit A, Holland PR, Goadsby PJ. Stimulation or lesioning of dopaminergic A11 cell group affects neuronal firing in the trigeminal nucleus caudalis. Cephalalgia. 2007;27:605.

54. Suzuki S, Suzuki K, Myamoto M, et al. Evaluation of contributing factors to restless legs syndrome in migraine patients. $J$ Neurol. 2011;258(11):2026-2035

55. Varkey E, Cider A, Carlsson J, Linde M. Exercise as migraine prophylaxis: a randomized study using relaxation and topiramate as controls. Cephalalgia. 2011;31(14):1428-1438.

56. Aukerman MM, Aukerman D, Bayard M, et al. Exercise and restless legs syndrome: a randomized controlled trial. J Am Board Fam Med. 2006;19(5):487-493.
Journal of Parkinsonism \& Restless Legs Syndrome

\section{Publish your work in this journal}

Journal of Parkinsonism and Restless Legs Syndrome is an online, open access, peer-reviewed journal. The journal publishes review articles, historical reviews, original research articles, case reports, letters to the editor, clinical teaching cases, neuroradiology highlights, neuropathology highlights, neuropsychiatry highlights, autobiographies, conference
Dovepress

proceedings, abstracts and book reviews. The manuscript management system is completely online and includes a very quick and fair peerreview system, which is all easy to use. Visit http://www.dovepress.com/ testimonials.php to read real quotes from published authors. 